\title{
Exploring Fun as a Job Resource: The Enhancing and Protecting Role of a Key Modern Workplace Factor
}

\author{
Katerina Georganta $^{1} \cdot$ Anthony Montgomery $^{1}$
}

Accepted: 6 November 2016 / Published online: 28 November 2016

(C) Springer International Publishing AG 2016

\begin{abstract}
Workplace fun, defined as the result of organic or organized activities that cause enjoyment in the workplace, has become increasingly important for both organizations and employees. Efforts to create a fun workplace are rooted in the notion that such experiences can contribute positively to the affective, cognitive and behavioral functioning of employees. Conceptualising workplace fun as a job resource two functions of fun are revealed; its enhancing role and its protective role. Workplace fun as a job resource can function as a social support mechanism and have a significant impact in buffering job demands while at the same time increasing positive outcomes through job engagement. We propose a theoretical model that helps better understand its function as well as its necessity and offer propositions that can help future research. Furthermore, taking into consideration the literature on the negative side of fun, we examine trust as an important moderator of fun's results on key outcomes and freedom of expression as a key prerequisite for workplace fun. Finally we have identified nudging, job crafting, and appreciative inquiry as potential avenues for promoting organic and organized activities that can contribute to a culture that supports workplace fun.
\end{abstract}

Keywords Workplace fun $\cdot$ Job resource $\cdot$ Job engagement $\cdot$ Wellbeing $\cdot$ Performance

\section{Exploring Fun as a Job Resource: The Enhancing and Protecting Role of a Key Modern Workplace Factor}

During the last decades, the corporate and consulting world has shown considerable interest in the phenomenon of fun in the workplace and a great amount of reflective

Katerina Georganta

katerina.georganta@gmail.com

1 School of Social Sciences, Humanities and Arts, Department of Educational and Social Policy, University of Macedonia, Egnatia 156, 54006 Thessaloniki, Greece 
pieces on how we can inject fun into the workplace have been published in the business and management literature (e.g. Rasmusson 1999; Riordan 2013; Urquhart 2005). The majority of these articles on fun, while not evidence-based, highlight the importance that people give to fun, and the fact that they consciously seek to indulge in it and continuously gravitate towards it, as noted by Cameron (2008). Lately, studies regarding workplace fun have been published in the academic literature developing the knowledge on the issue, revealing its problematic sides and setting the ground for new research and applications. For example the work of Karl and colleagues has laid the foundations for the empirical study of fun in the workplace (e.g. Karl et al. 2008; Karl et al. 2005) by both exploring attitudes of employees towards it and its effects on organizational variables. Tews and colleagues, Fluegge, McDowell and others (Bolton and Houlihan 2009; Fluegge-Woolf 2014; McDowell 2005; Tews et al. 2013, 2014) have provided more evidence on the impact of fun on wellbeing and key organizational issues, while others like Fleming and colleagues and Plester and colleagues have developed the concept even more by exploring its dark side (Fleming 2005; Fleming and Sturdy 2009; Plester 2009; Plester et al. 2015).

In this paper we present workplace fun as a job resource. Job resources are aspects of the job that help employees achieve work goals either with direct positive effects on positive outcomes or by buffering the effects of job demands (Demerouti et al. 2001). We suggest that workplace fun can be considered a job resource as it functions in both these ways; it can enhance positive outcomes and/or protect against demands. To achieve the aforementioned, we have divided our paper into three substantive sections that address; (1) fun as a job resource, (2) potential applications in the workplace, and (3) the limits of fun. In the first part of our paper we explore the enhancing and promoting functions by analysing the literature on workplace fun so far. In the second part of our paper we discuss how fun as a valuable resource can be promoted in the workplace, by exploring nudging, appreciative inquiry and job crafting as possible ways to effectively implement workplace fun initiatives. In the last part of our paper we present the negative side of fun and review the literature on aspects of fun that might be problematic when attempting to promote it in the workplace. Finally, based on these three sections, we present a theoretical model and four propositions that need to be examined in future research to more adequately understand the mechanisms of fun in relation to individual and organizational functioning.

The first objective of this paper is to collate the existing knowledge on fun and conceptualize it as a job resource. This conceptualization will help to demonstrate the possible implications of workplace fun for employees' wellbeing and organizational outcomes like performance. The second objective is to highlight the antecedents for the manifestation of positive workplace fun by building on the findings of the literature.

\section{What is Fun?}

Researchers have proposed several definitions of fun in the context of work. According to Ford et al. (2003a) a fun work environment is one that "intentionally encourages, initiates, and supports a variety of enjoyable and pleasurable activities that positively impact the attitude and productivity of individuals and groups" (p. 22). McDowell (2005, p. 9) defines fun at work as "engaging in activities not specifically related to the job that are enjoyable, 
amusing or playful", and a fun climate as an organizational climate that supports fun at work. According to McDowell's conceptualization, a fun climate includes activities like management support for fun, socializing with co-workers, celebrating at work, and having personal freedoms at work. Peluchette and Karl (2005) talk about the experience of fun and define it as the extent to which a person perceives the existence of fun in their workplace (p. 269). Fluegge defines fun as "any social, interpersonal, or task activities at work of a playful or humorous nature which provide an individual with amusement, enjoyment, or pleasure" (Fluegge 2008, p. 5). Lamm and Meeks (2009, p. 614) define workplace fun as activities that are playful, social, interpersonal, recreational, or task activities intended to provide amusement, enjoyment, or pleasure. For Strömberg and Karlsson (2009) workplace fun consists of humour rituals like joke telling, physical joking practices (pokes, tickles, jostles, grapples, dances, tactics of scaring people), clowning, nicknaming and using satire to create a fun workplace. Strömberg and Karlsson (2009) refer to these behaviours as organic fun comparing it to organized fun or managed fun, which refers to activities like celebrating personal events and professional milestones, social events, games, competitions and community involvement (Chan 2010; Ford et al. 2003a; 2004; Karl et al. 2005, 2008). Plester et al. (2015) have identified task related fun, which is fun that employees experience while performing their work tasks.

The above definitions present both generic and specific activities and behaviours that are evaluated as fun. At the same time the activities and behaviours are diverse, ranging from just using nicknames to getting involved in community events, and they are happening at all three levels; the individual, the group and the organizational. These heterogeneous definitions make it difficult to determine what fun is, but they do depict the many different uses of fun in the literature which are a result of the many activities and behaviours that can be considered fun. The definitions are limited to presenting a few activities and behaviours, which reflect the problems inherent in trying to find a comprehensive definition, as what is fun is both subjective and context related (Owler et al. 2010). In the literature, three main clusters of fun activities and behaviours have already been identified helping researchers to better understand and operationalize the concept of fun; managed (fun activities initiated or supported by the organization), organic (activities that the employees engage in by themselves), and task related, but, little has been done so far to clearly distinguish among them (Plester et al. 2015). Adding to the above, we know little regarding the interconnections among the three categories of fun activities and behaviours; for example how is managed fun related to organic fun, or is there a difference between fun activities organized by the employees themselves and fun activities organized by the management, resulting in a fourth category, that we can call organized fun and differentiate it from managed fun? According to Plester et al. (2015) all three forms of fun (organic, managed and task) may take place simultaneously but also compete with each other in terms of time invested, preference and appropriateness. It is a clear that we need to develop a typology of fun to understand it better. Furthermore, an important observation by Pryor et al. (2010) with the Workplace Fun Continuum model, is that fun is a continuum from "no fun to fun" compared to an all or nothing evaluation of a situation. This observation adds one more dimension in the difficulty of categorizing an activity or behaviour as fun. Finally, the experience of fun may be influenced by individual differences. For example, Karl et al. (2007) found that people's attitudes and their personality traits predict the level of fun experienced in the workplace. 
When trying to understand fun, it is important to acknowledge the importance of two closely related concepts, play and humour, which are often used interchangeably with the concept of fun to describe situations. Fun is an important factor when play is discussed, as fun seems to be the most common evaluation for playing (Huizinga 1955; Tökkäri 2015; Vanderschuren 2010). Play is an important aspect of work life (Mainemelis and Altman 2010), especially considering that the boundaries between work and play are quite often not very clear (Yee 2006). There is a trend to incorporate playing and having fun in the business world not as a disruption from work tasks but rather as a positive addition to organizational functioning (BrightHR 2016; Costea et al. 2005). Activities that are conceptualized as play are also often considered fun and can have a positive impact on psychological health. For example, Proyer (2013) found that the fun factor of playfulness is correlated with positive psychological status, life satisfaction and an active way of life. Furthermore, we have the potential to better understand workplace fun if we study its relation with humour. Humour is often a critical component in fun events in the workplace, and is defined as "amusing communications that produce positive emotions and cognitions in the individual, group, or organization" (Romero and Cruthirds 2006, p. 59). The use of humour in the workplace has been studied extensively and has been found to correlate with the quality of functioning under stress (Bizi et al. 1988) and to help in the regulation of emotions (Samson and Gross 2012). Employees view the use of humour as a way to deal with boredom and routine in the workplace, especially in low skilled jobs, time passes faster by developing peer relationships (Korczynski 2011). Interestingly, we don't ask employees whether they are enjoying humour or playing, we tend to ask them whether they are having fun. This suggests that investigating fun is the appropriate avenue to understand shared workplace positive affect.

To sum up the above, we conceptualize fun in the workplace as the result of organic or organized activities that cause enjoyment; these activities might be interactions that contain humour or playing with co-workers. Humour, in the form of jokes, spontaneous conversational humour and accidental or unintentional humour (Martin 2007), and play are events that might trigger a fun evaluation of certain situations and label an event or an interaction as fun.

\section{Fun as a Job Resource}

Although diverse, the definitions of workplace fun have in common a crucial factor, which is the relation of fun activities with positive feelings. It has been proposed that fun could be considered a job resource (Fluegge 2008; Georganta 2012; Tews et al. 2013) and it has been positively related to job engagement, which Maslach and Leiter (1997) define as a positive state characterized by energy, involvement and efficacy and has been considered the direct opposite of burnout and an indicator of wellbeing (Bolton and Houlihan 2009; Fluegge 2008; Fluegge-Woolf 2014; Simms 2007). Congruently, the Job Demands-Resources Model (Demerouti et al. 2001) is a model that has been widely used to describe the factors that affect wellbeing in the workplace. Specifically, the interactions between job demands and job resources play an important role; according to this model, due to the imbalance between the demands that an employee must face and the resources provided by the organization, people experience stress and other health problems. 
The job demands concept refers to the psychological, social or organizational aspects of work, as well as physical activities taking place in the workplace, which require prolonged physical and / or psychological effort or skills to achieve the work objectives and not reduce performance (Schaufeli and Bakker 2004, p. 296). Employees can replenish the extra effort that is needed in order to fulfil their tasks, with a break, by alternating tasks, or by performing less demanding activities. However, when this reset is insufficient or ineffective, it creates a long-term situation that gradually exhausts the employees physically and / or psychologically.

On the contrary, the resources offered by the organization can protect the employees from stress and promote positive effects, such as increased efficiency and motivation. The job resources are described as the physical, psychological, social, or organizational aspects of the job that are either functional in achieving work goals, reduce job demands or stimulate personal growth, learning, and development (Schaufeli and Bakker 2004, p. 296). Job resources create incentives for the employees and have a positive impact on desired effects such as employee wellbeing and engagement and mitigate the negative impact of job demands. Through job engagement (a condition characterized by vigour and active participation) the employees have a sense of connection with the activities in their organization and see themselves as capable to face any demand. Organizations that offer many resources promote the willingness of workers to devote effort and use their abilities to perform their duties. Thus job resources are used to buffer against the problems the employees face (Bakker et al. 2005; de Jonge et al. 2008; Xanthopoulou et al. 2007) and reduce the physiological and psychological costs that are associated with work. However there isn't one recipe for everyone, but it is important to correspond and apply appropriate interventions depending on the type of business, work tasks and other needs.

In the context of the Job Demands-Resources Model fun can function as a job resource. This happens because of its dual role in the workplace; fun can be protective and enhancing. A fun work environment has the potential to harness behaviours that are already occurring, and act as a preventive or protective mechanism against the inevitable stress associated with the increasingly demanding workplaces. At the same time, by offering a fun workplace, an organization may be able to enhance or create positive attitudes, feelings and behaviours towards it, for example in the form of job engagement. These ideas seem to be widespread; for example, Ford et al. (2003a), in a survey of human resources managers across USA, asked the participants to rate several fun activities and behaviours in terms of their frequency and rate the effect of fun work environments on a list of organisational outcomes. They found that fun in the workplace was perceived by the human resources managers as beneficial. The participants of the study, related fun to positive organizational variables such as commitment, performance, employee retention, enthusiasm, satisfaction, strength of the organizational culture, and decreases in anxiety, stress and mistakes.

Both organic and managed fun can be considered job resources. In the organizational level, managed fun is a job resource directly allocated by the organization. An organization can promote fun activities by offering funding, time or human resources for it. Organic fun can also be considered a job resource which the organization offers in an indirect way. As organic fun stems from the employees themselves, organizations can support it by offering a fun accepting work environment, or by creating situations where organic fun can be manifested. Ford et al. (2003b) have already suggested that a fun 
work environment is linked to both explicit and implicit managerial cues, with explicit referring to management policies, procedures, and formal reward systems and implicit referring to management actions, informal rewards and recognitions, praise, and criticism. Fun related personal resources, like a playful personality or humour may strengthen the results of the organizational level job resources (Kohn and Schooler 1982).

\section{Enhancing Role of Fun on Work-Related Outcomes}

Fun is expected to enhance desirable outcomes through positive affect. Indeed, fun has been found to highly correlate with positive affect (Fluegge-Woolf 2014) and as a pleasurable and positive experience it can potentially result in mood changes reflecting the positive interaction among a person and their environment. Watson et al. (1988) suggest that high positive affect is characterised by enthusiasm, high energy levels, mental alertness, show of interest, joy and determination. Positive affect has significant benefits in numerous outcomes, like happiness (Fredrickson and Joiner 2002), organizational citizenship behaviour (Williams and Shiaw 1999), attention scope (Fredrickson 2001) and task persistence (Tsai et al. 2007).

The evidence suggesting that fun can have a positive impact at work can be reviewed under four key areas; employees' subjective wellbeing, attitudes towards the organization, group dynamics, and contextual performance.

\section{Subjective Wellbeing}

In the literature there are three types of subjective wellbeing that are mostly studied: evaluative wellbeing, which can be considered as attitudes towards one person's (Kahneman and Krueger 2006); affective wellbeing, mostly referring to positive and negative feelings; and eudemonic wellbeing which has to do with meaning, autonomy, control and connectedness. Evaluative wellbeing is mostly understood through people's evaluations regarding their life satisfaction, job satisfaction and other cognitive assessments. Affective wellbeing is a capture of a person's feelings and can encompass both positive and negative experiences. As Csikszentmihalyi and Hunter (2003) noted these feelings can be captured at a given point in time and might not last more than several moments. Eudemonic wellbeing is an evaluation of whether people's underlying psychological needs, such as meaning, autonomy, control and connectedness (Ryff 1989) are covered. Meeting these needs can contribute towards wellbeing.

Fun by definition is related to positive, enjoyable and pleasure generating events. The literature so far only suggests that fun can contribute to affective subjective wellbeing, as the evidence is scarce. For example, Baptiste (2009) interviewed senior managers in a governmental agency and found that fun was included in their definitions of psychological wellbeing at work, while Fluegge-Woolf (2014) described, how positive fun events can lead to positive affective reactions.

Fun events are common in everyday life. These events can be conceptualized as momentary experiences that result in certain affective, cognitive and behavioural outcomes. Building on the literature so far and the episodic nature of fun, as well as the notion in Csikszentmihalyi's and Hunter's (2003) theory that wellbeing can be understood in terms of single events that create affective reactions, we expect that fun events will have a significant effect on both moods and feelings, manifesting this way 
improved affective well-being. It is important to note here that a growing body of research shows that the level of subjective wellbeing fluctuates significantly on a within-person level. For example, Bakker et al. (2013) studied intra-individual, daily fluctuations in subjective wellbeing (in terms of happiness, vigour, state of being recovered). Results showed that $59 \%$ of the variance in happiness, $66 \%$ of the variance in vigour, and $88 \%$ of the variance in recovery before sleep (i.e., a combination of feeling relaxed and recovered) could be attributed to fluctuations on a within-person and day level. Another example is the study of Ilies and Judge (2002), where employees completed momentary job satisfaction measures at different times during the day for a period of four weeks. Results showed that the within-individual variance for daily job satisfaction was $36 \%$. These fluctuations of subjective wellbeing can be attributed to very specific events, activities, social interactions, or other "momentary" indicators that vary within individuals, on a day-to-day basis. For instance, Dimotakis et al. (2010) showed that momentary positive interactions in the workplace had a positive effect on daily positive affect at work, whereas momentary negative interactions in the workplace were positively related to daily negative affect at work. Fun events in the workplace can lead to the above described fluctuations in employee affective wellbeing.

\section{Attitudes towards the Organization and the Job}

A fun and relaxing work environment may have a positive impact on people's perceptions, emotions, and motivations (Amabile and Kramer 2007) leading to positive attitudes towards the organisation, translating to evaluative wellbeing. Many researchers have supported this notion, especially in relation to experienced workplace fun and job satisfaction (Fisher 2000; Karl and Peluchette 2006a, 2006b; Karl et al. 2007; Peluchette and Karl 2005; Tews et al. 2013). Similarly, Lundin et al. (2002) report that after introducing a fun philosophy at a hospital, results of an in-house survey showed that the number of employees expressing "strong" satisfaction changed from $25 \%$ to $75 \%$ within a year. Tews et al. (2013) found significant positive correlations between fun activities and management support for fun with affective commitment. Tews et al. (2013) also found a low but significant negative correlation between management support for fun and turnover, while later (Tews et al. 2014) they also found that socializing with coworkers was negatively related to negative turnover. Furthermore, being considered a fun workplace has been found to be positively associated with organizational attraction (Pierce et al. 2012). Tews et al. (2014) have showed that fun activities may be of great value particularly in entry-level jobs with a relatively young workforce.

\section{Group Dynamics}

Fun could be a key to facilitating human relations and nurturing connectivity with all the positive effects that it involves (Losada and Heaphy 2004). Beck (1997) in written descriptions of nurses' experiences in using humour in providing nursing care, found that people that had fun seemed to also experience sense of belonging to the group, acceptance and better connection to each other. The use of humour and having fun with co-workers and others is considered one of the characteristics of a good day at work (Jackson 2005). The nurses that were interviewed in Jackson's study, mentioned that 
being able to share a laugh with a co-worker even without the use of humour, made them perceive higher levels of teamwork in their group and reported that they are getting along well with their co-workers. Strömberg and Karlsson (2009) used a variety of methods including observations, field notes, and individual and group interviews in a food preparation company, and found that the employees were constantly creating through organic fun, a working environment that seemed to enhance solidarity among them, increase feelings of acceptance and strengthen their group's cohesion. Recently, Mesmer-Magnus et al. (2012) in their meta-analysis of positive humour found that supervisor humour also relates in a positive way to workgroup cohesion.

Fun may function as a form of identification with an individual or a group, and may play an important role regarding their belonging within the organization, defined as "the experience of personal involvement in a system or environment so that persons feel themselves to be an integral part of that system or environment" (Hagerty et al. 1992, p.173). If we consider the subjective nature of fun, the perception of the same activity or behaviour as fun, can lead to perceived similarity and familiarity. These two characteristics of interpersonal relations have been found to cultivate a sense of belonging (Zhao et al. 2012). Occurrence of fun in a group might be a way for the people to express themselves and can lead the individual to feel as a part of that group. If people perceive as fun the same activities or the same situations, this can cause them to think that they have other characteristics in common and will probably lead to identification by self-categorizing themselves as part of the same group (Turner et al. 1987). Plester and Hutchison (2016) using a qualitative design found that "fun facilitates connectedness with others at work" (p. 345), as it increases enjoyment on the team level. Considering the above, fun's impact on group dynamics may be the key to explaining a variety of its positive effects on outcomes, like turnover.

\section{Contextual Performance}

Considering the high correlation among fun events and positive affect and job engagement that have been found in the literature, we do expect fun to have a positive impact on contextual performance related variables (Motowidlo and Van Scotter 1994). Contextual performance or extra-role performance are behaviours that are usually not referred to in job descriptions or role requirements reports. Motowidlo and Van Scotter (1994) have distinguished two types of performance in their model; task performance and contextual performance. Behaviours that have to do with altruism, courtesy, conscientiousness, sportsmanship, compliance and civic virtue in the workplace, like organisational citizenship behaviour (Organ \& Konovsky 1989), have been used as indicators of contextual performance (de Boer et al. 2015) and have been shown to have an effect on the social and affective climate of the organisation and attitudes towards it (see Podsakoff et al. 2000 for a review and meta-analysis). Good relationships among employees, in the terms of trust, cohesiveness and perceived support have been considered as antecedents of organizational citizenship behaviour (Podsakoff et al. 2000), leading scholars to hypothesize that relationships that include other types of positive activities, like fun, could lead to increased organizational citizenship behaviour. For example, Fluegge (2008), Fluegge-Woolf (2014), Lamm and Meeks (2009) and Tews et al. (2013) found that the frequency of fun activities, the existence of personal freedoms and general perceptions of a fun environment (global fun) have been 
positively correlated with organizational citizenship behaviour, which can be explained by fun's enhancing role in the group relations and specifically in the feeling of belonging to the team. Furthermore, Karl and Peluchette (2006a, 2006b) found that employees who have experienced workplace fun are more likely to be motivated to work with others and provide better customer service, extending the positive effects of fun from the colleagues to the customers. Moreover, Avolio et al. (1999) found that transformational leadership, which consists of extra - role leadership behaviours, like attending individually to each employee, is related to experiencing a fun workplace.

But how is fun associated with contextual performance? In the context of the Job Demands and Recourse model, job engagement is the main motivational process that links the resources with the positive outcomes. Workplace fun has been linked with job engagement notably in Plester's and Hutchison's (2016) approach, who found that employees associated the concept of engagement when talking about fun, and associated both with positive feelings. In specific, Plester and Hutchison (2016) revealed that the two concepts are linked through the positive feelings that are generated towards the organization and the team, which in turn increase organizational engagement. Both workplace fun and job engagement are characterized by enthusiasm and positive energy that function as motivational processes and help employees deliver more positive outcomes.

Improving employee performance can be challenging for organizations and many interventions targeting either the individual or the group have been developed to address this issue. While the literature on workplace fun promotion and its association with performance is in its infancy and there are a few studies so far demonstrating its relevance, we suggest that maintaining a fun climate might help alleviate toxic environments and improve wellbeing that will in turn effect individual and organizational results. As Fluegge-Woolf (2014) highlighted, an organization that supports the occurrences of fun events in the workplace will be able to capitalize on the positive affect and high activation that these will create, and improve employees' contextual performance and innovative behaviour (Madrid et al. 2014).

Taking into consideration the above, a fun activity or behaviour seems to be a positive experience, resulting in beneficial outcomes for the individual and the organization.

Proposition 1a: Fun through job engagement will enhance the positive aspects of a workplace having an impact on individual, group and organizational level variables. Proposition 1b: Fun will have an impact on job engagement through positive affect.

\section{Protective Role of Fun at the Individual and Organizational Level}

While work can be highly rewarding, it can also drain people emotionally (dealing with clients or facing an abusive manager are some examples) and it has several adverse effects as it can increase the likelihood of employees' turnover or early retirement intentions, poor self-rated health, poor workability, and stress symptoms (Harju et al. 2014). One of the main propositions of the Job Demands and Resources model is that the resources buffer the negative effects of the demands (Bakker et al. 2003). Fun seems to function in a similar way; having the freedom to have fun in the workplace maybe be a catalytic factor in terms of preventing the negative consequences of the demands in the individual and organizational level in two ways; via coping with stress 
and by protecting from emotional exhaustion. Fun may function as a short mental fix, which would be carried through the day, and make it easier to deal with demands that cause stress, emotional exhaustion and negative affect.

Consistent with the above, Karl and Peluchette (2006a, 2006b) in a series of surveys found that employees who reported that they experienced workplace fun were more likely to experience less stress and were less likely to be absent or leave the organization. Fun can play a critical role in helping people cope with work stress, as 'sharing a laugh' can be helpful in many cases (Charman 2013; Plester 2009). Fun could help relieve feelings of anxiety, and even insecurity as well as creating a sense of belonging in a group, with consequences in many sensitive issues that the organization has to deal with, like the introduction of new employees and their socialization process or "surviving" transition periods. Furthermore, Karl et al. (2007) found that people that were experiencing more fun at work reported less emotional exhaustion.

Conceptualized as a job resource, and taking into consideration the buffering effects of job resources to phenomena like stress, fun is expected to ameliorate burnout, and especially decrease emotional exhaustion. We expect that a fun activity or behaviour could also decrease the need for recovery from work, because employees who will have experienced fun incidents in the workplace will not need to detach from it after the work hours, but in fact remember it and share the positive climate with others outside of work. Moreover, we suggest that the feeling of having a good day at work could easily be transferred at home, while also increasing feelings of anticipation of going back (to work) where fun is accepted, especially organic fun. Thus we assume that different amounts of fun could assist in a stronger positive effect of crossover/ spillover as defined by Rodríguez-Muñoz et al. (2014) and reduce the need for recovery from work.

Fun can function in such a way as it can be used as a form of social support. Taking into consideration the way that fun affects the dynamics of groups and our argument that having fun creates bonds, we can hypothesize that these elements will manifest in difficult cases when employees are under pressure or face difficult situations in the same way as other social support behaviours manifest. For example, playing a game, sharing a funny story or gossiping can create experiences and form dyads or small groups that share a common background. In cases of stress these dyads or groups could be deployed as a support network to help relieve the strain. The interactions that took place during fun incidents can function as a basis for future communications in work matters or in cases that relief is needed. This relief can take the form of either a new fun event, like telling a joke, or other types of support like information providing. The key concept is that sharing fun experiences categorizes the people in the same network (or group), making them available for offering or receiving support by increasing the sense of belonging.

Proposition 2: Fun can protect employees against the negative impact associated with high job demands by functioning as a buffering social support mechanism.

\section{Promoting Fun in the Workplace}

Could fun be a part of human resource development strategies and a management practice? In the following section, we review three key strategies in the field of work and organizational psychology that can be utilized to promote fun in the workplace. 


\section{Nudging}

An indirect way that might be effective in promoting fun in the workplace could be a nudge, which Thaler and Sunstein $(2008$, p. 6) define as any aspect of the choice architecture that alters people's behaviour in a predictable way without forbidding any options or significantly changing their economic incentives. Simply put, nudges are changes in the way alternatives are presented in order for the desired choices to be more frequently chosen. While Thaler and Sunstein give great emphasis to default choices, the major characteristic of nudges is that they don't compromise choice, which, as discussed above, in the case of fun is crucial. Imposing fun activities on employees might sometimes have the opposite results or even lead to cynicism (Fleming 2005; Fleming and Sturdy 2009), as the need to regulate behaviour and emotions is not reduced. The movement towards a fun promoting culture should respect the freedom of choice, especially when we talk about managed fun. We should not consider as a default that employees want to participate in organized by others fun activities, but we should function with the default of free choice among alternatives or not choosing anything at all. Tolerance is the key here, so that employees who prefer to not participate in organized fun activities for any reason should not be stigmatized. Respite breaks seem to be helpful in maintaining positive affect (Trougakos et al. 2008), for example a micro break, especially during stressful or intense work days can protect the wellbeing of the employees by helping dilute the tension and regain strength. Organizations could offer the alternative of a lunch time walk or play a game, for example, instead of letting the employees merely sit in front of a computer screen. Taking a respite from work during work time to engage in fun activities should be promoted or offered as a choice but not imposed or involve the extra burden of longer work hours. An organization should offer the alternatives for having fun but not impose managed fun to their employees. Nudges would be the difference between managed and organized fun, which as mentioned above refers to fun activities organized by the employees themselves.

\section{Job Crafting / Break Crafting}

Fun has been associated with increased feelings of autonomy (Fleming 2005; Fleming and Sturdy 2009, 2011) and building on the assumption that control is a variable that has been historically associated with increased wellbeing (Karasek 1979) we assume that by offering employees control over certain aspects of their work related to fun, we can have favourable outcomes in terms of wellbeing. Employees who adopt an active role, by using their resources and redesign aspects of their work (Bakker 2010) are not passive recipients of their work environment and can shape their own work context. This type of involvement in job design, is called job crafting, and Wrzesniewski and Dutton (2001, p. 179) define it as "the physical and cognitive changes individuals make in the task or relational boundaries of their work". Job crafting could be useful in laying the foundations for fun to exist. Being able to craft one's job is a resource by itself, as it entails freedom of choice. Aspects of work that could be designed by the employees themselves in this meaning could also refer to their rest and respite times. Being able to choose not only the tasks but also the breaks, the content of the breaks, as well as craft the interpersonal relationships someone experiences during their break, might function 
as a significant job resource. For example, employees can craft their breaks by requesting the provision of a ping pong table in their workspace or by taking a break at the same time with a colleague with whom they have fun.

\section{Appreciative Inquiry}

Another classic approach could entail using the method of appreciative inquiry (Cooperrider and Srivastva 1987). During the last decade, appreciative inquiry has been extensively used as a method for positive organizational change by focusing on the parts of the organization that function as energy sources and exploring new ways to utilize them. For example Verleysen et al. (2015) found that organizations who use appreciative inquiry differ significantly from organizations that don't use it in terms of psychological capital development, and specifically in relation to optimism and resilience. By focusing on what is already being done to have fun, people could envision what more they can do and find and implement ways to achieve it. This could serve as a collective/ participatory bottom up intervention for promoting fun in the workplace that will bring to the surface many voices, creating in this way a shared understandings of things, and thus making boundaries and thin lines more clear. Using this approach, characteristics of the workplace that are considered positive are kept while new elements are added. For example, employees could form groups with the objective to identify moments or share stories of events in which they had a lot of fun and examine their context. Organized or managed events that were successful in the past and were considered fun can be repeated laying the foundation of a series of related initiatives. Furthermore, the context of organic activities can be explored and help the employees understand the sources of fun in their workplace. The appreciative inquiry procedure of focusing on what to grow, inquiring positively on the cause of success, building on strengths and working together to implement (Vanstone 2011) is well suited to nurturing a fun promoting culture, mostly as the ideas emanate from the employees themselves.

A fun workplace is certainly not easy to achieve due to the complexity of the phenomenon itself, especially its subjective and spontaneous nature. Bottom up approaches combined with management support should have the best results in terms of creating a work environment that people can have fun into. Even seemingly simple ideas can become complex in the implementation process when experiencing fun is the goal.

\section{The Negative Side of Fun}

Promoting workplace fun might be expected to result in purely positive outcomes. But there might be a negative side to it in terms of keeping employees from work, annoying others while there is increased workload, or in the form of negative or racist comments about others and even the development of cliques which may lead to mistrust. A common negative side, though, might be the consequences of having to be the protagonist of a fun event. Making 'fun' of someone can be enjoyable and bonding for the actor and their co-actors but might have negative consequences for the person receiving the fun comments or being the epicentre of the negative jokes. Also, fun by nature seems to be characterized by spontaneity, thus generating a contradiction when talking about organized or managed fun. Furthermore, workplace fun might seem as a 
luxury for many employees and organizations due to excessive demands that they believe that they need to deal with first. The above highlight three issues to take into consideration when implementing fun initiatives; the fact that the line between offending and fun can be a thin one, the risks of controlled fun, and the incongruity that might arise when the management of an organisation leaves energy draining demands unaddressed while promoting fun initiatives.

\section{The Need for Boundaries}

Supporting the above, Plester (2009) spent one month inside four companies that had declared their interest in exploring, maintaining and creating workplace fun and found evidence highlighting the importance of boundaries in fun related activities. She observed employees, analysed electronic forms of humour, she recorded examples of humour and fun verbatim, and collected brochures, e-mails, cartoons, posters, web texts and material with interviews. The result of this extensive mixed methods study was to reveal the importance that the employees themselves give to boundaries when having fun. These boundaries not only derive from the organizational culture of each company (for example some cultures may be more tolerant towards certain types of behaviours) but also have to do with the time and space and most importantly the type of fun related activity in question (e.g. a racist joke). In a later analysis of their data Plester and Hutchison (2016) found that employees considered fun as both helpful and distractive, showing how complex workplace fun is, especially in terms of task performance.

Where does this need for boundaries stem from? Fun is subjective and contextual and its ethics seem blurry for this reason. The need for boundaries reflects the fact that fun can certainly have a negative impact if all actors are not respected. If we would like to analyse the concept a little bit deeper, being able to have fun in the workplace entails feeling free and safe to express oneself and reveals a background of respect, which is a key issue here. When employees have fun by mimicking for example their supervisor there are two levels of analysis to be mindful of; first is the relationship of the employees with each other and the second concerns the relationship of the employees with their supervisor (Korczynski 2011). Making fun of the supervisor entails trust and lack of respect at the same time; there is trust and feelings of safety among the employees, but there is a hint of disrespect towards the supervisor or the organization. This leads to an interesting paradox concerning the experience of fun.

\section{Controlled Fun}

Fleming and his colleagues (Fleming 2005; Fleming and Sturdy 2009, 2011) mentioned what they called neo-normative control programmes of fun in organizations which try to imitate positive non-work experiences and that this may not always be effective; in case studies, they found that although some employees internalised the philosophy of a culture of fun, some others perceived these programmes as patronizing and degrading. Individuals could intuitively understand that such programmes were cynically motivated and aimed at results other than the employees' wellbeing, like achieving marketing goals (Waren and Fineman 2007). Statler et al. (2011) have noted the paradox of intentionally using play in the workplace as a serious job. Furthermore, in one of The Economist's blogs Schumpeter (2010) states that "as soon as fun becomes part of a 
corporate strategy it ceases to be fun and becomes its opposite-at best an empty shell and at worst a tiresome imposition" and that "compulsory fun is nearly always cringemaking". Taking into consideration the above and the definition elements of fun we can understand why controlled fun like described in the above studies can't be effective. As fun is the expression of the true self and freedom of speech is one of its key antecedents, any attempt to promoting it without expressing corresponding values might have opposite results. However, understanding the underlying elements, the basic pillars of fun, which are freedom and trust, can inform our approach to managing people. For example, we expect that the relationship between fun and job engagement, burnout, need for recovery from work and performance will be different depending on the levels of trust that is perceived in the organization or among the group. Fun and trust seem to have a cyclical relationship, with people who trust each other to be able to have more fun in the workplace while people who have fun are cultivating trust. The absence of trust might lead to cynicism as we have described above.

Managed fun has the potential to result in adverse outcomes, as it may be viewed as a burden rather than a resource. An organization that offers resources to help deal with the demands and protect the employees from stress is desirable and as we have argued above, fun can be one of these resources. But while fun seems to have positive effects on several variables, as a job resource we hypothesize that it only moderates the impact of demands on outcomes. Thus, it seems hard to accept it as a medicine for curing all ills in the organization, especially in situations where; demands are high and chronic, freedom of expression is a luxury and mistrust is present.

\section{Tackling Other Demands First}

In a workplace where there is an imbalance among demands and resources in favour of demands, what is the role of fun? Baptiste (2009) has warned us regarding "a silence in the fun at work literature" (p. 609) on this matter. By interviewing managers she found a widely accepted perception that many factors need to be addressed before a fun at work culture that aims at employees' wellbeing could be promoted. According to the senior managers that participated in the study, other aspects of employment needed to be addressed before fun at work interventions could be meaningful for their workplace. Taking into consideration the above, an emerging negative side of workplace fun is that organisations may attempt to promote workplace fun without trying to address basic work related problems like for example workload, time pressure, negative employment relations or abusive behaviours. A fun activity or behaviour can have a short-term, day level positive impact on mood or feelings, but in a workplace with excessive job demands if it is employed as a long-term wellbeing tool, it might not have the desired results, as it can only moderate the impact of demands on well-being. Long term wellness programmes should also decrease demands while increasing resources like workplace fun. To add to this, what emerged from Baptiste's study and from the series of studies by Fleming (Fleming 2005; Fleming and Sturdy 2009, 2011), was a hierarchy of needs in the workplace. Fun promoting programmes or managed fun, are not considered a basic workplace need, but they appear as a luxurious service on the top of the pyramid of needs or even as an extra, effort requiring demand. In these studies fun in the workplace, especially managed fun, sometimes generates cynicism, 
when employees consider that initiatives for fun events shouldn't be a first priority, and most importantly at the expense of initiatives for decreasing workload for example.

\section{Freedom of Expression}

Plester (2009) proposes that genuine workplace fun is spontaneous, contextual and has an unmanaged, liberated element that defies control. Congruently, Fineman (2006) notes that fun typically gains its "funness" from its spontaneity, surprise, and often subversion of the extant order. Also, Fleming and Sturdy (2009) conceptualized fun as an expression of the authentic self and associated it with diversity. Fun and concepts of freedom of expression are evident in the above. When talking about fun, freedom of expression seems to be a core factor which suggests that workplace fun, especially organic fun, is less likely to manifest in a workplace that doesn't practice freedom of expression. While managed fun can function without freedom of expression, the positive affective result of positive events will happen if the culture of the organization that favours emotional displays (Robert and Wilbanks 2012).

Proposition 3: Freedom of expression is a prerequisite of workplace fun.

\section{Trust}

Fun as described above seems to have a cyclical relation with trust, in the way that people in the workplace who trust each other seem to be able to have more fun in the workplace and at the same time people who have fun are cultivating trust. Plester and Hutchison (2016) found that workplace fun can contribute to better relationships in terms of psychological safety by increasing camaraderie, a notion that includes concepts like trust, loyalty and goodwill. The absence of trust might lead to cynicism. The organizational culture itself seems to play an important role. Owler et al. (2010) based on Schein's framework for understanding organizational culture described how espoused values (second level) like fun at work might not reflect the underlying assumptions and values that exist at a deeper organizational level (third level) and thus cause contradictions, incongruities and dissonance. The probability of controlled fun resulting in negative outcomes is possible when they do not reflect the values of the organization or when management is not perceived as benevolent. Opposite results might be generated if respect and dignity are not part of the equation (Fleming 2005) or when the needs of the employees are not taken into consideration (Everett 2011). We thus propose the following:

Proposition 4a: Trust will moderate the relationship between workplace fun and job engagement.

Proposition 4b: Trust will function as a distal indicator between job demands and negative outcomes.

To summarize, fun will function as a job resource in the workplace and will protect employees from job stress by buffering job demands, while at the same time it 
will enhance key aspects of work life via positively impacting affect, group dynamics, performance, and attitudes towards the organization. But when talking about fun we need to take into consideration the need for boundaries, with respect as the key element, as well as the risks that controlled fun carries. For a fun culture to exist and be effective, two key characteristics of the climate are important; trust and freedom of expression. In Fig. 1 we present a model that represents our ideas about the protective and enhancement potential of fun in the workplace.

\section{Discussion}

This paper has uncovered conceptual, theoretical, and empirical connections between workplace fun and organizational outcomes, and integrated them into the Job Demands and Resource Model. We conceptualized fun as a job resource and contribute to the literature in this area by elucidating how increasing organic, organized and managed fun can have direct and indirect effects on job engagement and other positive outcomes while buffering the negative effects of job demands on well-being. Also, we analyzed how fun can be an important indicator and determinant of workplace relationships.

\section{Theoretical Implications and Directions for Future Research}

Empirical and theoretical work in the domain of workplace fun originated in the disciplines of management science, organizational behaviour and service quality. This paper has related fun to relevant theories and broadened its usability by integrating the

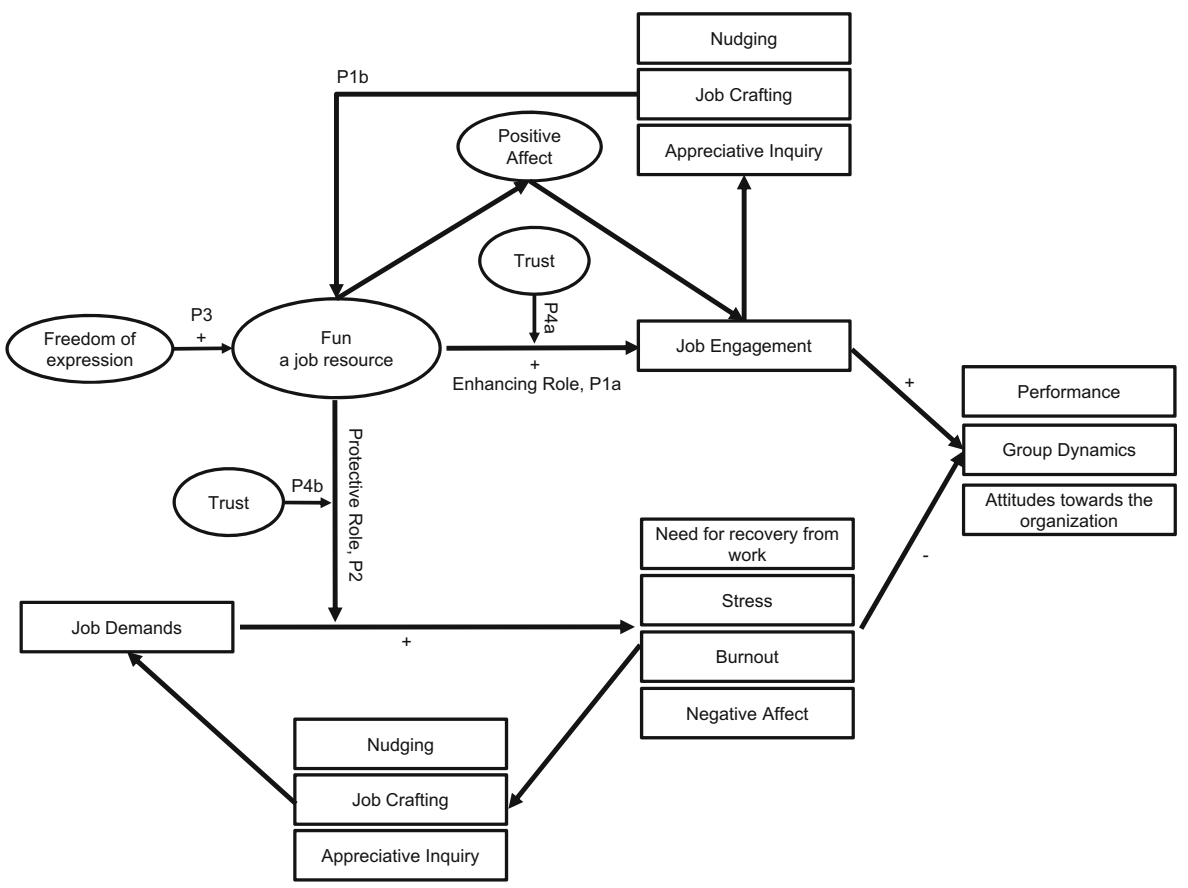

Fig. 1 "Theoretical model of workplace fun" 
phenomenon in a well-accepted model of work psychology, contributing to the growing literature on the topic by shedding light on the psychological processes that underlie it. In particular, we have explored the role of fun as a job resource through the lens of the Job Demands and Resources model and we have presented four propositions related to organic, organized and managed fun that can be tested by future researchers.

The majority of work on fun to date has identified the types of fun activities that have desired effects in a variety of variables like job engagement, job satisfaction and turnover, but has not fully identified the processes through which these are achieved. Yet, further understanding of the fun phenomenon in connection with issues of interest to the human resources management field could prove fruitful. By integrating fun in the JD-R model and conceptualizing it as a job resource we are setting the base for a better understanding of how, when and why workplace fun can have these desired effects, because the JD-R model explains the positive effects of job resources on positive organizational outcomes through a process of motivation. We thus suggest that workplace fun can function as a motivational factor if considered as a job resource, contributing to an increase in the outputs the employees receive from their work environment, which according to Equity Theory (Adams 1963) may lead to increased perceived input (the source of the positive input can be the organization, leading to organization oriented positive outcomes, or a person -e.g. colleague- resulting in individual oriented positive outcomes). Future studies need to focus on understanding the process through which workplace fun impacts outcomes and we encourage researchers to do so in the theoretical framework that we have already outlined.

Furthermore, much of the research connected with fun has been focused on the outcomes, but we have relatively few empirical studies that can help us understand the factors that enable and encourage the manifestation of fun in the workplace. In our analysis we examined the role of freedom of expression as an antecedent to the expression of fun. Thus, future research should focus on exploring the antecedent conditions for workplace fun. We expect that fun will manifest itself when positive conditions exist and contribute to them, in line with Fredrickson's (2001) broaden-andbuild theory. Also, given the relational nature of fun, studies should give more emphasis to team level variables like sense of belonging, psychological safety and trust, that we suggest function as moderators in the associations between workplace fun and other variables. These social context variables can be the basis for explaining the process and mechanisms through which fun has an impact on outcomes. Similarly, boundary conditions to the effects of workplace fun like imposed fun, or fun that crosses subjective limits set by the participants of fun activities or the actors of fun behaviours should be taken into consideration in future studies.

Future research should further illuminate to what extent objective business indicators (e.g. work performance, customer satisfaction, sickness absenteeism and sales) are predicted by workplace fun. It would also be interesting to examine whether workplace fun is associated with objective health outcomes, e.g. cardiovascular risks. Furthermore, we urge future research to disentangle the negative outcomes of workplace fun, by studying its relation to rudeness, incivility and bullying, as well as to reduced direct productivity due to lost work hours.

Individuals experience fun while doing their work. Such task related fun may function as an important job characteristic that can motivate employees and lead to 
desirable outcomes (Plester et al. 2015). The JD-R model has its roots in Hackman and Oldham's (1976) job characteristics model, which places meaningfulness of the job in its core, defined in terms of skill variety, task identity and task significance. Fun infused activities are imbued with meaningfulness. Based on the above, future research should examine the degree to which fun may influence perceptions of meaningfulness with regard to in-role tasks and extra-role activities.

On a more general note, studying workplace fun instead of only humour consists of a fresh and more substantial look on what brings pleasure to the modern organization, as new ways of having fun, like playing games during working hours have emerged in the last decades. These activities often do not include humorous interactions per se, but enable enjoyment and pleasure similar to what humour begets.

\section{Practical Implications}

Fun as a phenomenon involves complex relations that can be organically driven (Strömberg and Karlsson 2009), and it originates and grows in workplaces that valorise freedom and trust. Fun as a natural tendency of humans should be nurtured and promoted in light of the objective of cultivating the wellbeing of people at work. An organization that will choose to follow this path should first address the issues of freedom of speech and trust, while ensuring that important basic workplace needs of the employees are also met. In the absence of the above, attempts to create a fun workplace might not result in the desired outcomes. The above are certainly in need of further examination, as fun, as an explicit concept is much too serious to be taken lightly. In this paper we suggest that three strategies will be more effective in promoting fun in the workplace; nudging, job crafting / break crafting and appreciative inquiry. These three ways respect the key antecedents of workplace fun that our review has revealed; trust, freedom of expression and choice. In terms of managed fun specifically, offering alternatives, instead of imposing them, is the significant factor in delivering effective fun programs.

Management support for fun appears to be the most crucial factor if the goal is to shift to a fun promoting culture or even proceed with fun initiatives, as studies so far suggest that it is an important component of perceived fun (e.g. Tews et al. 2013, 2014). The managers' role should be such that they can address the balance between work and leisure (Tews et al. 2014) while applying the fun promoting notion. Managers should take into consideration the negative effects of the absence of fun in the workplace and view the promotion of a healthy fun culture not only as an investment in the employees' psychological capital and consequently in the human capital of their organization, but also as a way to protect the organization itself, as organizations and teams obviously benefit from fun activities and behaviours. Thus, encouraging fun is enticing from a managerial perspective. Managers that are aware that fun is an indicator of the social and psychological undercurrents in a team (when fun is absent, it can be an indication of a disturbance in good relationships) may be readily able to spot the absence or withdrawal of fun manifestations. Therefore, by examining the prevalence or absence of fun, managers can have information about the wellbeing of their teams and employees. Furthermore, managers can properly intervene to prevent damage by creating opportunities for fun. These opportunities though should be explicitly purposed for fun and make sure that they are not perceived simply as extra work for the employees. As 
tempting as it might be, leaders should not attempt to force fun activities, as this is opposite to the very notion of what fun can be.

Fun can enhance the sense of belonging in the team as it fosters behaviours beyond mere collaboration that can lead to meaningful social support. Social support which has been linked to good health, as it buffers the negative effects of stress, is a well-known job resource, but according to Berkman et al. (2000) social support is protective when it occurs in the context of a naturally occurring social network into which the individual is well integrated. Fun infused social relationships can prove significant during crisis management at the team level. The concept of social capital is relevant at this point as it refers to the benefits and obligations that being a member of a network entails. Workplace fun thus can contribute to an organization's social capital (Glover et al. 2005).

Studies clearly suggest that fostering the wellbeing of the employees is in the best interest of the employer, as organizational performance is related to the level of employee well-being (e.g. Breevaart et al. 2015; Christian et al. 2011; Demerouti et al. 2005; Gorgievski et al. 2014; Judge et al. 2001; Taris 2006; Wright and Cropanzano 2000). Although fun is a positive addition to work life, it does not always translate into positive outcomes. Practically speaking, the more fun activities happen in the workplace the more work hours are spent in tasks not related directly to work. Also, higher performance is sometimes thought to be associated with less fun, as there is the idea that employees who have fun are distracted from their in-role tasks, and don't actually do their job. But if we take into consideration the effects that fun might have on job engagement we should be able to shed light on more complex associations with performance. By integrating workplace fun in the JD-R model, we propose that as a job resource workplace fun will have an impact on job engagement, which in turn effects in-role and extra-role performance (e.g. Bakker and Bal 2010; Halbesleben and Wheeler 2008; (Harter et al. 2002; Salanova et al. 2005). The empirical evidence so far explicitly shows the connection between types of fun and job engagement, supporting our argument.

Leaders must also be aware of circumstances where fun activities are neither desired nor contribute to positive outcomes. For example, in one sense, fun activities could be seen by the organization and the employee as a reduction of resources (like time and energy), thus creating an aversion to them. In another sense, fun activities can be seen as contributing to a positive climate. The point here is to ensure that employees retain a sense of balance between what is gained by organic, organized and managed fun activities and what is lost, taking into consideration the potential indirect and long term effects of fun on the individual, team and organizational level, for example in terms of job engagement, as discussed above. We can appreciate that some employers and employees may view the promotion of fun with scepticism and also associate it either with a less professional approach in the workplace or a topic not deserving of serious consideration. It is up to decision makers of the organization to weight the benefits and loses and decide whether employees engaging in fun activities is an investment that the organization needs.

On the person level, playfulness has been considered a personality trait, and it is used to explain the heterogeneous play behaviour observed, while many studies have tried to reveal the attributes of a playful person (e.g. Barnett 1990, 2011). We thus expect playfulness to have an important role in terms of attitudes towards workplace fun, and be a key factor to differentiate the outcomes of workplace fun among 
employees. Furthermore, Lamm and Meeks (2009) found generational differences in terms of fun that moderate the association between workplace fun and individual outcomes. The above individual and generational differences should be taken into consideration along with organisational factors when promoting workplace initiatives or designing wellness programs as key moderating variables that can affect the outcomes.

While fun can create a positive climate in the workplace, practitioners should be cautious of encouraging strategies that focus on enhancing job resources without altering the level of job demands. According to the JD-R model, job resources buffer the effect of job demands on strain. However, what happens in situations where job resources are unable to buffer high levels of strain? In such situations, fun activities may not be enough to tackle the impact of demands, thus making it increasingly important to understand what happens in terms of strain when job demands and job resources are both high (Van Vegchel et al. 2005). When is increasing resources, like promoting more fun activities, useful by itself and when tackling several demands first is necessary? Based on Equity Theory the connection between the resources that the organization provides and what the employee gives back is important to understand, but this might have a limitation. Engaging the Human Resources departments to promote workplace fun while monitoring the demands can feed the need for balance in giving and taking and result in more energy invested by the employees towards the organization that they work for and the teams they belong to.

\section{Concluding Remarks}

Positivity is not the first item on the agenda of many organizations, at its effects in the workplace are not clear, especially regarding performance or more broadly profit. The economic crisis, had also affected this, as both in the US and Europe, the workplace is set to become more demanding as fewer resources and more stress push wellbeing weighing scales more out of kilter. Thus, the need to identify which positive phenomena contribute to wellbeing is even more important. Fun is a positive phenomenon that can function as an effective job resource and can help relieve stress, as well as creating a sense of belonging in a group, with consequences in many sensitive issues that the organization has to deal with, like coping with high demands. Positive feelings that emerge from fun activities have an impact at both the individual and organizational level (Fredrickson 1998). Moreover, in a workplace where fun is the norm, a positive organizational culture will be created where freedom of expression can lead towards a healthier organization.

At present it is difficult to find studies that directly connect fun at work with performance. However, we can see that fun is linked to important team processes. For example, fun plays an important role in how teams function. Across diverse occupations, the factor that has been most strongly associated with effective team working is psychological safety (Edmondson and Lei 2014). Most recently, Google investigated what makes its own teams effective via its Project Aristotle (Duhigg 2016). The results of their investigation suggested that 'psychological safety' - whereby team members have a shared belief that it is safe to take risks and share a range of ideas without the fear of being humiliated - emerged as crucial. As we have argued in the first part of this 
paper, fun is directly associated with trust, freedom of expression and sense of belonging. Thus, fun is an important part of building psychological safety. Finally, psychological safety is a significant job resource which returns us to the JD-R model.

\section{Compliance with Ethical Standards}

Conflict of Interest The authors declare that they have no conflict of interest.

\section{References}

Adams, J. S. (1963). Towards an understanding of inequity. Journal of Abnormal and Social Psychology, 67, 422-436. doi:10.1037/h0040968.

Amabile, T. M., \& Kramer, S. J. (2007). Inner work life: understanding the subtext of business performance. Harvard Business Review, 85(5), 72-83.

Avolio, B. J., Howell, J. M., \& Sosik, J. J. (1999). A funny thing happened on the way to the bottom line: humour as a moderator of leadership style effects. The Academy of Management Journal. doi:10.2307 1257094 .

Bakker, A. B. (2010). Engagement and job crafting: engaged employees create their own great place to work. In S. L. Albrecht (Ed.), Handbook of employee engagement: perspectives, issues, research and practice (pp. 229-244). UK: Edward Elgar.

Bakker, A. B., \& Bal, P. M. (2010). Weekly work engagement and performance: a study among starting teachers. Journal of Occupational and Organizational Psychology, 83, 189-206. doi:10.1348/096317909 X402596.

Bakker, A. B., Demerouti, E., Taris, T., Schaufeli, W. B., \& Schreurs, P. (2003). A multigroup analysis of the job demands-resources model in four home-care organizations. International Journal of Stress Management. doi:10.1037/1072-5245.10.1.16.

Bakker, A. B., Demerouti, E., \& Euwema, M. C. (2005). Job resources buffer the impact of job demands on burnout. Journal of Occupational Health Psychology. doi:10.1037/1076-8998.10.2.170.

Bakker, A. B., Oerlemans, W. G. M., \& Ten Brummelhuis, L. (2013). Becoming fully engaged in the workplace: what individuals and organizations can do to foster work engagement. In C. Cooper \& R. Burke (Eds.), The fulfilling workplace: the organization's role in achieving individual and organizational health (pp. 55-70). Surrey: Gower.

Baptiste, N. R. (2009). Fun and well-being: insights from senior managers in a local authority. Employee Relations. doi:10.1108/01425450910991758.

Barnett, L. A. (1990). Playfulness: definition, design, and measurement. Play and Culture, 3(4), 319-336.

Barnett, L. A. (2011). How do playful people play? Gendered and racial leisure perspectives, motives, and preferences of college students. Leisure Sciences: An Interdisciplinary Journal. doi: 10.1080/01490400.2011.606777.

Beck, C. T. (1997). Humour in nursing practice: a phenomenological study. International Journal of Nursing Studies. doi:10.1016/S0020-7489(97)00026-6.

Berkman, L. R., Glass, T., Brisette, I., \& Seeman, T. E. (2000). From social integration to health: Durkheim in thenew millenium. Social Science \& Medicine, 51, 843-857. doi:10.1016/S0277-9536(00)00065-4.

Bizi, S., Keinan, G., \& Beit-Hallahmi, B. (1988). Humour and coping with stress: a test under real-life conditions. Personality and Individual Differences. doi:10.1016/0191-8869(88)90128-6.

Bolton, S. C., \& Houlihan, M. (2009). Are we having fun yet? A consideration of workplace fun and engagement. Employee Relations. doi:10.1108/01425450910991721.

Breevaart, K., Bakker, A. B., Demerouti, E., \& Van den Heuvel, M. (2015). Leader-member exchange, work engagement, and job performance. Journal of Managerial Psychology, 30, 754-770. doi:10.1108/JMP03-2013-0088.

BrightHR (2016). It pays to play https://pages.brighthr.com/itpaystoplay-v2b.html.

Cameron, K. S. (2008). Paradox in positive organizational change. The Journal of Applied Behavioral Science. doi:10.1177/0021886308314703. 
Chan, S. C. H. (2010). Does workplace fun matter? Developing a useable typology of workplace fun in a qualitative study. International Journal of Hospitality Management. doi:10.1016/j.ijhm.2010.03.001.

Charman, S. (2013). Sharing a laugh: the role of humour in relationships between police officers and ambulance staff. International Journal of Sociology and Social Policy. doi:10.1108/01443331311308212.

Christian, M. S., Garza, A. S., \& Slaughter, J. E. (2011). Work engagement: a quantitative review and test of its relations with task and contextual performance. Personnel Psychology, 64, 89-136. doi:10.1111/j.17446570.2010.01203.x.

Cooperrider, D. L., \& Srivastva, S. (1987). Appreciative inquiry in organizational life. In R. W. Woodman \& W. A. Pasmore (Eds.), Research in organizational change and development 1 (pp. 129-169). Stamford: JAI Press.

Costea, B., Crump, N., \& Holm, J. (2005), Dionysus at work? The ethos of play and the ethos of management. Culture and Organization, 11, 139-151. doi:10.1080/14759550500091069.

Csikszentmihalyi, M., \& Hunter (2003). Happiness in everyday life: the uses of experience sampling. Journal of Happiness Research. doi:10.1023/A:1024409732742.

de Boer, B. J., van Hooft, E. A. J., \& Bakker, A. B. (2015). Self-control at work: its relationship with contextual performance. Journal of Managerial Psychology. doi:10.1108/JMP-08-2012-0237.

de Jonge, J., Le Blanc, P. M., Peeters, M. C. W., \& Noordam, H. (2008). Emotional job demands and the role of matching job resources: a cross-sectional survey study among health care workers. International Journal of Nursing Studies. doi:10.1016/j.ijnurstu.2007.11.002.

Demerouti, E., Bakker, A. B., Nachreiner, F., \& Schaufeli, W. B. (2001). The job demands-resources model of burnout. The Journal of Applied Psychology. doi:10.1037/0021-9010.86.3.499.

Demerouti, E., Verbeke, W., \& Bakker, A. B. (2005). Exploring the relationship between a multidimensional and multifaceted burnout concept and self-rated performance. Journal of Management, 31, 186-209. doi: $10.1177 / 0149206304271602$.

Dimotakis, N., Scott, B. A., \& Koopman, J. (2010). An experience sampling investigation of workplace interactions, affective states, and employee well being. Journal of Organizational Behavior. doi:10.1002 /job.722.

Duhigg, C. (2016). What Google learned from its quest to build the perfect team. The New York Times. Retrieved from http:/www.nytimes.com/2016/02/28/magazine/what-google-learned-from-its-quest-tobuild-the-perfect-team.html.

Edmondson, A. C., \& Lei, Z. (2014). Psychological safety: the history, renaissance, and future of an interpersonal construct. Annual Review of Organizational Psychology and Organizational Behavior, 1, 23-43. doi:10.1146/annurev-orgpsych-031413-091305.

Everett, A. (2011). Benefits and challenges of fun in the workplace. Library Leadership and Management, 25(1), 1-10.

Fineman, S. (2006). On being positive: concerns and counterpoints. The Academy of Management Review. doi:10.5465/AMR.2006.20208680.

Fisher, C. D. (2000). Mood and emotions while working: missing pieces of job satisfaction? Journal of Organizational Behavior. doi:10.1002/(SICI)1099-1379(200003)21:2<185::AID-JOB34>3.0.CO;2-M.

Fleming, P. (2005). Workers' playtime? Boundaries and cynicism in a "culture of fun" program. The Journal of Applied Behavioral Science. doi:10.1177/0021886305277033.

Fleming, P., \& Sturdy, A. (2009). Just be yourself! Towards neo-normative control in organisations? Employee Relations. doi:10.1108/01425450910991730.

Fleming, P., \& Sturdy, A. (2011). 'Being yourself' in the electronic sweatshop: new forms of normative control. Human Relations. doi:10.1177/0018726710375481.

Fluegge, E. R. (2008). Who put the fun in functional? Fun at work and its effects on job performance (Unpublished doctoral dissertation). Gainesville: University of Florida.

Fluegge-Woolf, E. R. (2014). Play hard work hard. Management Research Review. doi:10.1108/MRR-112012-0252.

Ford, R. C., McLaughlin, F. S., \& Newstrom, J. W. (2003a). Questions and answers about fun at work. Human Resource Planning, 26(4), 18-33.

Ford, R. C., McLaughlin, F. S., \& Newstrom, J. W. (2003b). Creating and sustaining fun work environments in hospitality and service organizations. Journal of Human Resources in Hospitality \& Tourism. doi:10.1300/J171v04n01_02.

Ford, R. C., Newstrom, J. W., \& McLaughlin, F. S. (2004). Making workplace fun more functional. Industrial and Commercial Training. doi:10.1108/00197850410532131.

Fredrickson, B. L. (1998). What good are positive emotions? Review of General Psychology. doi:10.1037 /1089-2680.2.3.300. 
Fredrickson, B. L. (2001). The role of positive emotions in positive psychology: the broaden-and-build theory of positive emotions. The American Psychologist. doi:10.1037/0003-066X.56.3.218.

Fredrickson, B. L., \& Joiner, T. (2002). Positive emotions trigger upward spirals toward emotional well-being. Psychological Science. doi:10.1111/1467-9280.00431.

Georganta, K. (2012). Fun in the workplace: a matter for health psychologists? The European Health Psychologist, 14(2), 41-45 http://www.ehps.net/ehp.

Glover, T. D., Shinew, K. J., \& Perry, D. (2005). Association, sociability, and civic culture: the democratic effect of community gardening. Leisure Sciences, 27(1), 75-92. doi:10.1080/01490400590886060.

Gorgievski, M. J., Moriano, J. A., \& Bakker, A. B. (2014). Relating work engagement and workaholism to entrepreneurial performance. Journal of Managerial Psychology, 29, 106-121. doi:10.1108/JMP-062012-0169.

Hackman, J. R., \& Oldham, G. R. (1976). Motivation through the design of work: test of a theory. Organizational Behavior and Human Performance. doi:10.1016/0030-5073(76)90016-7.

Hagerty, B. M. K., Lynch-Sauer, J., Patusky, K. L., Bouwsema, M., \& Collier, P. (1992). Sense of belonging: a vital mental health concept. Archives of Psychiatric Nursing. doi:10.1016/0883-9417(92)90028-H.

Halbesleben, J. R. B., \& Wheeler, A. R. (2008). The relative roles of engagement and embeddedness in predicting job performance and intention to leave. Work and Stress, 22, 242-256. doi:10.1080 /02678370802383962.

Harju, L., Hakanen, J., \& Schaufeli, W. B. (2014). Job boredom and its correlates in 87 Finnish organizations. Journal of Occupational and Environmental Medicine. doi:10.1097/JOM.0000000000000248.

Harter, J. K., Schmidt, F. L., \& Hayes, T. L. (2002). Business-unit-level relationship between employee satisfaction, employee engagement, and business outcomes: a meta-analysis. The Journal of Applied Psychology, 87, 268-279. doi:10.1037/0021-9010.87.2.268.

Huizinga, J. (1955). Homo Ludens: a study of the play element in culture. Boston: Beacon Press.

Ilies, R., \& Judge, T. A. (2002). Understanding the dynamic relationship between personality, mood, and job satisfaction: a field experience-sampling study. Organizational Behavior and Human Decision Processes. doi:10.1016/S0749-5978(02)00018-3.

Jackson, C. (2005). The experience of a good day: a phenomenological study to explain a good days experienced by a newly qualified RN. International Journal of Nursing Studies. doi:10.1016/j. ijnurstu.2004.05.015.

Judge, T. A., Thoresen, C. J., Bono, J. E., \& Patton, G. K. (2001). The job satisfaction-job performance relationship: a qualitative and quantitative review. Psychological Bulletin, 127, 376-407. doi:10.1037 /0033-2909.127.3.376.

Kahneman, D., \& Krueger, A. B. (2006). Developments in the measurement of subjective well-being. The Journal of Economic Perspectives. doi:10.1257/089533006776526030.

Karasek, R. A. (1979). Job demands, job decision latitude, and mental strain: implications for job redesign. Administrative Science Quarterly. doi:10.2307/2392498.

Karl, K. A., \& Peluchette, J. V. (2006a). How does workplace fun impact employee perceptions of customer service quality? Journal of Leadership and Organizational Studies. doi:10.1177/10717919070130020201.

Karl, K. A., \& Peluchette, J. V. (2006b). Does workplace fun buffer the impact of emotional exhaustion on job dissatisfaction? A study of health care workers. Journal of Behavioral and Applied Management. doi: $10.1177 / 1548051811431828$.

Karl, K., Peluchette, J. V., Hall-Indiana, L., \& Harland, L. (2005). Attitudes toward workplace fun: a three sector comparison. Journal of Leadership and Organizational Studies. doi:10.1177/107179190501200201.

Karl, K. A., Peluchette, J. V., \& Harland, L. (2007). Is fun for everyone? Personality differences in healthcare providers' attitudes toward fun. Journal of Health and Human Services Administration, 29(4), 409-447.

Karl, K. A., Peluchette, J. V., \& Hall, L. M. (2008). Give them something to smile about: a marketing strategy for recruiting and retaining volunteers. Journal of Nonprofit \& Public Sector Marketing. doi:10.1080 /10495140802165360.

Kohn, M. L., \& Schooler, C. (1982). Job conditions and personality: a longitudinal assessment of their reciprocal effects. The American Journal of Sociology. doi:10.1086/227593.

Organ, D. W., \& Konovsky, M. (1989). Cognitive versus affective determinants of organizational citizenship behavior. The Journal of Applied Psychology. doi:10.1037/0021-9010.74.1.157.

Korczynski, M. (2011). The dialectical sense of humour: routine joking in a taylorized factory. Organization Studies. doi:10.1177/0170840611421256.

Lamm, E., \& Meeks, M. D. (2009). Workplace fun: the moderating effects of generational differences. Employee Relations. doi:10.1108/01425450910991767.

Losada, M., \& Heaphy, E. (2004). The role of positivity and connectivity in the performance of business teams: a nonlinear dynamics model. The American Behavioral Scientist. doi:10.1177/0002764203260208. 
Lundin, S., Christensen, J., Paul, H., \& Strand, P. (2002). Fish! Tales: real-life stories to help transform your workplace and your life. New York: Hyperion.

Madrid, H. P., Patterson, M. G., Birdi, K. S., Leiva, P. I., \& Kausel, E. E. (2014). The role of weekly highactivated positive mood, context, and personality in innovative work behavior: a multilevel and interactional model. Journal of Organizational Behavior. doi:10.1002/job.1867.

Mainemelis, C., \& Altman, Y. (2010). Work and play: new twists on an old relationship. Journal of Organizational Change Management. doi:10.1108/jocm.2010.02323aaa.001.

Martin, R. A. (2007). The psychology of humor: an integrative approach. Burlington: Elsevier Academic Press.

Maslach, C., \& Leiter, M. P. (1997). The truth about burnout. San Francisco: Jossey Bass.

McDowell, T. (2005). Fun at work: scale development, confirmatory factor analysis, and links to organizational outcomes (Unpublished doctoral dissertation). CA: Alliant International University.

Mesmer-Magnus, J., Glew, D. J., \& Viswesvaran, C. (2012). A meta-analysis of positive humour in the workplace. Journal of Managerial Psychology. doi:10.1108/02683941211199554.

Motowidlo, S. J., \& Van Scotter, J. R. (1994). Evidence that task performance should be distinguished from contextual performance. The Journal of Applied Psychology. doi:10.1037/0021-9010.79.4.475.

Owler, K., Morrison, R., \& Plester, B. (2010). Does fun work? The complexity of promoting fun at work. Journal of Management \& Organization. doi:10.1017/S1833367200002005.

Peluchette, J. V., \& Karl, K. A. (2005). Attitudes toward incorporating fun into the health care workplace. The Health Care Manager, 24(3), 268-275.

Pierce, C. A., Karl, K. A., \& Brey, E. T. (2012). Role of workplace romance policies and procedures on job pursuit intentions. Journal of Managerial Psychology. doi:10.1108/02683941211205808.

Plester, B. (2009). Crossing the line: boundaries of workplace humour and fun. Employee Relations. doi:10.1108/01425450910991749.

Plester, B., \& Hutchison, A. (2016). Fun times: the relationship between fun and workplace engagement. Employee Relations. doi:10.1108/ER-03-2014-0027.

Plester, B., Cooper-Thomas, E., \& Winquist, J. (2015). The fun paradox. Employee Relations. doi:10.1108 /ER-04-2013-0037.

Podsakoff, P. M., MacKenzie, S. B., Paine, J. B., \& Bachrach, D. G. (2000). Organizational citizenship behaviors: a critical review of the theoretical and empirical literature and suggestions for future research. Journal of Management. doi:10.1016/S0149-2063(00)00047-7.

Proyer, R. T. (2013). The well-being of playful adults: adult playfulness, subjective well-being, physical wellbeing, and the pursuit of enjoyable activities. European Journal of Humour Research, 1(1), 84-98 http://www.europeanjournalofhumour.org/.

Pryor, M. G., Pryor Singleton, L., Taneja, S., \& Humphreys, J. H. (2010). Workplace fun and its correlates: a conceptual inquiry. International Journal of Management, 27(2), 294-302.

Rasmusson, E. (1999). A funny thing happened on the way to work. Sales and Marketing Management, 151(3), 97-98.

Riordan, C. M. (2013). We all need friends at work http://blogs.hbr.org/2013/07/we-all-need-friends-at-work/.

Robert, C., \& Wilbanks, J. (2012). The wheel model of humour: humour events and affect in organizations. Human Relations. doi:10.1177/0018726711433133.

Rodríguez-Muñoz, A., Sanz-Vergel, A. I., Demerouti, E., \& Bakker, A. B. (2014). Engaged at work and happy at home: a spillover-crossover model. Journal of Happiness Studies. doi:10.1007/s10902-013-9421-3.

Romero, E. J., \& Cruthirds, K. W. (2006). The use of humor in the workplace. Engineering Management Review, IEEE. doi:10.1109/EMR.2006.261378.

Ryff, C. D. (1989). Happiness is everything, or is it? Explorations on the meaning of psychological well-being. Journal of Personality and Social Psychology. doi:10.1037/0022-3514.57.6.1069.

Salanova, M., Agut, S., \& Peiro, J. M. (2005). Linking organizational resources and work engagement to employee performance and customer loyalty: the mediation of service climate. The Journal of Applied Psychology, 90, 1217-1227. doi:10.1037/0021-9010.90.6.1217.

Samson, A. C., \& Gross, J. J. (2012). Humour as emotion regulation: the differential consequences of negative versus positive humour. Cognition \& Emotion. doi:10.1080/02699931.2011.585069.

Schaufeli, W. B., \& Bakker, A. B. (2004). Job demands, job resources, and their relationship with burnout and engagement: a multi-sample study. Journal of Organizational Behavior. doi:10.1002/job.248.

Schumpeter (2010). Down with fun. The Economist, September 16. Retrieved from http:/www.economist. com/node/17035923.

Simms, J. (2007). Having fun is engaging. People Management, 13(20), 10.

Statler, M., Heracleous, L., \& Jacobs, C. D. (2011). Serious play as a practice of paradox. The Journal of Applied Behavioral Science. doi:10.1177/0021886311398453. 
Strömberg, S., \& Karlsson, J. C. (2009). Rituals of fun and mischief: the case of the Swedish meatpackers. Employee Relations. doi:10.1108/01425450910991776.

Taris, T. W. (2006). Is there a relationship between burnout and objective performance? A critical review of 16 studies. Work and Stress, 20, 316-334. doi:10.1080/02678370601065893.

Tews, M. J., Michel, J. W., \& Stafford, K. (2013). Does fun pay? The impact of workplace fun on employee turnover and performance. Cornell Hospitality Quarterly. doi:10.1177/1938965513505355.

Tews, M. J., Michel, J. W., \& Allen, D. G. (2014). Fun and friends: the impact of workplace fun and constituent attachment on turnover in a hospitality context. Human Relations. doi:10.1177/0018726713508143.

Thaler, R. H., \& Sunstein, C. R. (2008). Nudge: improving decisions about health wealth and happiness. New Haven: Yale University Press.

Tökkäri, V. (2015). Organizational play: within and beyond managing. Qualitative Research in Organizations and Management: An International Journal. doi:10.1108/QROM-11-2013-1181.

Trougakos, J. P., Beal, D. J., Green, S. G., \& Weiss, H. M. (2008). Making the break count: an episodic examination of recovery activities, emotional experiences and positive affective displays. The Academy of Management Journal. doi:10.5465/AMJ.2008.30764063.

Tsai, W. C., Chen, C. C., \& Liu, H. L. (2007). Test of a model linking employee positive moods and task performance. The Journal of Applied Psychology. doi:10.1037/0021-9010.92.6.1570.

Turner, J. C., Hogg, M. A., Oakes, P. J., Reicher, S. D., \& Wetherell, M. S. (1987). Rediscovering the social group: a self-categorization theory. Oxford: Blackwell.

Urquhart, J. (2005). Creating a fun workplace: when hokey pokey is what it's all about. Healthcare Registration, 14(11), 3-5.

Van Vegchel, N., de Jonge, J., Bosma, H., \& Schaufeli, W. B. (2005). Reviewing the effort-reward imbalance model: drawing up the balance of 45 empirical studies. Social Science \& Medicine, 60, 1117-1131. doi:10.1016/j.socscimed.2004.06.043.

Vanderschuren, L. J. M. J. (2010). How the Brain Makes Play Fun. American Journal of Play, 2(3), 315-337 http://www.journalofplay.org/.

Vanstone, C. (2011). An introduction to Appreciative Inquiry. http://www.sfjuk.com/wp-content/uploads/2013 /06/Intro-to-Appreciative-Inquiry-Nov-2011.pdf.

Verleysen, B., Lambrechts, F., \& Van Acker, F. (2015). Building psychological capital with appreciative inquiry: investigating the mediating role of basic psychological need satisfaction. The Journal of Applied Behavioral Science. doi:10.1177/0021886314540209.

Waren, S., \& Fineman, S. (2007). Don't get me wrong it's fun here but...: Ambivalence and paradox in a 'fun' work environment. In R. Westwood \& C. Rhodes (Eds.), Humour work and organization (pp. 92-112). London: Routledge.

Watson, D., Clark, L. A., \& Carey, G. (1988). Positive and negative affectivity and their relation to anxiety and depressive disorders. Journal of Abnormal Psychology. doi:10.1037/0021-843X.97.3.346.

Williams, S., \& Shiaw, W. T. (1999). Mood and organizational citizenship behavior: the effects of positive affect on employee organizational citizenship behavior intentions. The Journal of Psychology. doi:10.1080/00223989909599771.

Wright, T. A., \& Cropanzano, R. (2000). Psychological well-being and job satisfaction as predictors of job performance. Journal of Occupational Health Psychology, 5, 84-94. doi:10.1037/10768998.5.1.84.

Wrzesniewski, A., \& Dutton, J. E. (2001). Crafting a job: Revisioning employees as active crafters of their work. The Academy of Management Review. doi:10.5465/AMR.2001.4378011.

Xanthopoulou, D., Bakker, A. B., Demerouti, E., \& Schaufeli, W. B. (2007). The role of personal resources in the job demands-resources model. International Journal of Stress Management. doi:10.1037/10725245.14.2.121.

Yee, N. (2006). The labor of fun: how video games blur the boundaries of work and play. Games and Culture. doi:10.1177/1555412005281819.

Zhao, L., Lu, Y., Wang, B., Chau, P. Y. K., \& Zhang, L. (2012). Cultivating the sense of belonging and motivating user participation in virtual communities: a social capital perspective. International Journal of Information Management. doi:10.1016/j.ijinfomgt.2012.02.006. 